\title{
Basal Insulin Inadequacy versus Failure - Using Appropriate Terminology
}

\author{
Sanjay Kalra ${ }^{1}$ and Yashdeep Gupta ${ }^{2}$
}

1. Department of Endocrinology, Bharti Hospital, Karnal, India; 2. Department of Endocrinology, All India Institute of Medical Sciences, New Delhi, India

\begin{abstract}
This editorial focuses on appropriate terminology related to basal insulin therapy. The authors analyse current usage of 'basal insulin failure', and propose 'basal insulin inadequacy' as a better descriptor for persons not responding to basal insulin alone. The pharmacokinetic and pharmacodynamic differences between various basal insulin preparations are highlighted. Based upon these, a drug-specific definition for insulin inadequacy is suggested, instead of a generic class-based labelling.
\end{abstract}

\section{Keywords}

Basal insulin failure, basal insulin inadequacy, degludec, detemir, glargine, neutral protamine Hagedorn, type 2 diabetes, terminology

Disclosure: Sanjay Kalra and Yashdeep Gupta have no conflicts of interest to declare. No funding was received for the publication of this article. open Access: This article is published under the Creative Commons Attribution Noncommercial License, which permits any non-commercial use, distribution, adaptation and reproduction provided the original author(s) and source are given appropriate credit.

Received: 9 July 2015 Published Online: 18 August 2015 Citation: European Endocrinology, 2015;11(2):79-80 DOI: 10.17925/EE.2015.11.02.79

Correspondence: Sanjay Kalra, Department of Endocrinology, Bharti Hospital, Karnal, India. E: brideknl@gmail.com

Basal insulin therapy is recommended as a first-line injectable therapy in persons with type 2 diabetes who do not respond to metformin monotherapy. Insulin works to control fasting glycaemia, and it is expected that metformin (with or without other drugs) will suffice apropos post-prandial euglycaemia. In many patients, however, basal insulin is unable to achieve adequate glycaemic control. This has been termed basal insulin failure. However, in the light of newer developments, we suggest a more appropriate term, basal insulin inadequacy, and discuss how it can be used.

\section{Basal Insulin Failure}

According to the current American Diabetes Association (ADA)/ European Association for Study of Diabetes (EASD) guidelines, change of basal insulin therapy is indicated if the treatment strategy fails to achieve normal glycated haemoglobin $\left(\mathrm{HbA}_{1 \mathrm{c}}\right)$ in spite of adequate fasting control, or if $>0.5 \mu / \mathrm{kg} /$ day of basal insulin is required. ${ }^{1}$ Basal insulin failure has earlier been defined as the inability to achieve a pre-decided target glycaemic control, after optimisation of lifestyle modification measures and maximal titration of basal dose beyond which unacceptable hypoglycaemia will occur. ${ }^{2}$

\section{Basal Insulin Inadequacy}

The current nomenclature implies that basal insulin has 'failed', while actually it may have succeeded in achieving fasting euglycaemia. Thus a more appropriate terminology is 'basal insulin inadequacy'. This conveys a more accurate message that basal insulin is inadequate for the particular patient's need. Inadequacy avoids the negative connotation associated with the word 'failure'. It does not pass judgmental opinion on either the patient's efforts to manage lifestyle or the physician's choice of therapeutic strategy.

\section{Basal Insulin Dissimilarity}

All basal insulins are not alike. Each basal insulin and basal analogue has a unique structure, which contribute to specific pharmacokinetic and

\section{Table 1: Classification of Basal Insulins and Insulin Regimes}

\begin{tabular}{ll} 
Intermediate acting & Neutral protamine Hagedorn \\
\hline Long acting & Glargine, detemir \\
\hline Ultra-long acting & Degludec \\
\hline Of historical interest & Lente, semi-lente, ultra-lente
\end{tabular}

pharmacodynamic characteristics. ${ }^{3}$ These properties allow a systematic listing of basal insulin as intermediate-, long- and ultra-long-acting molecules (see Tables 1 and 2). The differences in duration of action, glycaemic variability and risk of hypoglycaemia, specifically nocturnal hypoglycaemia, may allow for substitution of one basal insulin for another, in case adequate control is not achieved with a particular preparation. Thus, a new strategy for intensification of therapy is available for persons not responding to basal therapy: a switch to a longer-acting basal insulin.

Such a therapy is supported by mechanistic studies, randomised controlled trials (RCTs) and meta-analysis. Insulin degludec, for example, has been shown to have a longer half-life and duration of action, with significantly less glycaemic variability than glargine. ${ }^{4}$

RCTs and meta-analyses report a significantly lower incidence of hypoglycaemia and nocturnal hypoglycaemia, while achieving better fasting glucose control, in persons randomised to insulin degludec compared with glargine..$^{5-8}$ Refractory patients, switched from glargine to degludec, have also been reported to achieve good glycaemic control in clinical practice..$^{910}$ Cost-effectiveness of such a shift is also found to be beneficial.11,12 Thus, the clinical phenomenon of 'basal insulin inadequacy' may be drug-specific. Inability of a particular basal insulin to achieve adequate glycaemic control does not imply that all basal insulins will be inadequate for the purpose. Applied to a patient not responding to glargine, the phrase 'basal insulin inadequacy' may not be valid for all basal insulins. 
Table 2: Comparison of Basal Insulins and Insulin Analogues

\begin{tabular}{|c|c|c|c|c|}
\hline Insulin & $\mathrm{NPH}$ & Glargine & Detemir & Degludec \\
\hline Structure & $\begin{array}{l}\text { Addition of protamine to } \\
\text { unmodified human insulin, in } \\
\text { quantity sufficient to complex } \\
\text { all insulin molecules }\end{array}$ & $\begin{array}{l}\text { Acidic long-acting analogue } \\
\text { with substitution of } \\
\text { asparagine with glycine at } \\
\text { A21, and addition of two } \\
\text { arginine residues at B30 }\end{array}$ & $\begin{array}{l}\text { Deletion of threonine at B30 } \\
\text { and addition of aliphatic fatty } \\
\text { acid to lysine at B29 }\end{array}$ & $\begin{array}{l}\text { Deletion of threonine at B30 } \\
\text { and addition of } 16 \text {-chain } \\
\text { carbon fatty di-acid to lysine } \\
\text { at B29 with glutamic acid as } \\
\text { a spacer }\end{array}$ \\
\hline Number of amino acids & 51 & 53 & 50 & 50 \\
\hline Appearance & Cloudy & Clear & Clear & Clear \\
\hline Onset of action & $2-3 h$ & $1-4 \mathrm{~h}$ & $1-4 \mathrm{~h}$ & - \\
\hline Half-life & - & $12.5 \mathrm{~h}$ & $12.5 \mathrm{~h}$ & $25 \mathrm{~h}$ \\
\hline Duration of action & Up to $18 \mathrm{~h}$ & Up to $24 \mathrm{~h}$ & $16-24 \mathrm{~h}$ & Up to $42 \mathrm{~h}$ \\
\hline Mechanism of protraction & Slow dissociation & $\begin{array}{l}\text { Precipitates form in } \\
\text { subcutaneous tissue and } \\
\text { dissociate slowly }\end{array}$ & $\begin{array}{l}\text { Reversible binding with } \\
\text { albumin and slow dissociation } \\
\text { of multimers }\end{array}$ & $\begin{array}{l}\text { Multi-hexamers form in } \\
\text { subcutaneous tissue and } \\
\text { dissociate slowly }\end{array}$ \\
\hline $\begin{array}{l}\text { Binding affinity to IGF-I receptor } \\
\text { (human insulin 100) }\end{array}$ & 100 & $641 \pm 51$ & $18 \pm 2$ & 2 \\
\hline $\begin{array}{l}\text { Binding affinity to insulin receptor } \\
\text { (human insulin 100) }\end{array}$ & 100 & $86 \pm 3$ & $16 \pm 1$ & $13-15$ \\
\hline Variability & High & Medium & Low & Very low \\
\hline $\begin{array}{l}\text { Ratio of exposure over first } 12 \mathrm{~h} \\
\text { and second } 12 \mathrm{~h} \text { after injection }\end{array}$ & - & $60: 40$ & $50: 50$ & $50: 50$ \\
\hline Risk of hypoglycaemia & May occur & LOW & Low & Minimal \\
\hline Risk of nocturnal hypoglycaemia & May occur & May occur & Minimal & Minimal \\
\hline Risk of weight gain & Yes & Yes & No & Minimal \\
\hline Injection-site reactions & Rare & $\begin{array}{l}\text { Possible, because of } \\
\text { acidic } \mathrm{pH}\end{array}$ & Rare & Rare \\
\hline Miscibility with rapid-acting insulin & Yes & No & No & Yes \\
\hline Miscibility with GLP1RA & No & Yes (with lixisenatide) & No & Yes (with liraglutide) \\
\hline Frequency of administration & Once to twice daily & Once daily & Once to twice daily & Once daily \\
\hline Timing of administration & At same time every day & At same time every day & At same time every day & At any time of the day \\
\hline
\end{tabular}

GLP1RA = glucagon-like peptide-1 receptors agonists; IGF-1 = insulin-like growth factor 1; NPH = neutral protamine Hagedorn. Modified with permission from Kalra S, Newer basal insulin analogues: degludec, detemir, glargine, J Pak Med Assoc, 2013;63(11):1442-4. ${ }^{3}$

We therefore suggest the following terminology and definitions:

- $\quad$ Basal insulin inadequacy may be defined as the inability of all basal insulin preparations, prescribed alone or in combination with various oral glucose-lowering drugs, to achieve pre-decided glycaemic targets, without causing unacceptable hypoglycaemia or weight gain, in spite of optimal lifestyle modification and maximal dose titration.

- Intermediate-, long-acting and ultra-long-acting insulin inadequacy may be used to describe persons who do not respond to maximal doses of NPH, glargine and detemir and degludec, respectively.
1. Inzucchi S, Bergenstal R, Buse J, et al., Management of hyperglycemia in type 2 diabetes, 2015: a patient centered approach update to a position statement of the American Diabetes Association and the European Association for the Study of Diabetes, Diabetes Care, 2015;38:140-9.

2. Buse JB, Bergenstal RM, Glass LC, et al., Use of twice-daily exenatide in basal insulin-treated patients with type 2 diabetes: a randomized, controlled trial, Ann Intern Med, 2011;154:103-12.

3. Kalra S, Newer basal insulin analogues: degludec, detemir, glargine, J Pak Med Assoc 2013;63:1442-4.

4. Heise T, Hermanski L, Nosek L, et al., Insulin degludec: four times lower pharmacodynamic variability than insulin glargine under steady-state conditions in type 1 diabetes, Diabetes Obes Metab, 2012;14:859-64.
5. Zinman B, Prillis-Tsimikar A, Cariou B, et al, Insulin degludec versus glargine in insulin naive patients with type 2 diabetes: a randomized treat to target trial (BEGIN Once Long), Diabetes Care, 2012:35:2464-71.

6. Ratner RE, Gough SCL, Mathieu C, et al., Hypoglycaemia risk with insulin degludec compared with insulin glargine in type 2 and type 1 diabetes: a pre-planned meta-analysis of phase 3 trials, Diabetes Obes Metab, 2013;5:175-84.

7. Kalra S, Insulin degludec: a significant advancement in ultralong-acting basal insulin, Diabetes Ther, 2013;4:167-73.

8. Kalra S, Unnikrishnan AG, Baruah M, et al., Degludec insulin: a novel basal insulin, Indian J Endocrinol Metab, 2011;15(Suppl. 1):S12-6.

9. Hamasaki $\mathrm{H}$, Yanai $\mathrm{H}$, Switching from insulin glargine to insulin degludec reduced $\mathrm{HbA1C}$, daily insulin doses and anti-insulin antibody in anti-insulin antibody-positive subjects with type 1 diabetes, Diabetes Metab, 2014:6:481-2.

10. Sinha B, Gangopadhyay KK, Ghosal S, Is insulin degludec more effective treatment for patients using high doses of insulin glargine but not attaining euglycemia? Some cas reports from India, Diabetes Metab Syndr Obes, 2014;7:225-8.

11. Evans M, Wolden M, Gundgaard J, et al., Cost-effectiveness of insulin degludec compared with insulin glargine in a basalbolus regimen in patients with type 1 diabetes mellitus in the UK, J Med Econ, 2014; 18:56-68.

12. Evans $\mathrm{M}$, Wolden $\mathrm{M}$, Gundgaard J, et al., Cost-effectiveness of insulin degludec compared with insulin glargine for patients with type 2 diabetes treated with basal insulin-from the UK health care cost perspective, Diabetes Obes Metab. 2014:16:366-75. 